\title{
The relationship between maternal adiposity and infant weight gain, and childhood wheeze and atopy
}

\author{
Katharine C Pike, ${ }^{1,2}$ Hazel M Inskip, ${ }^{3,4}$ Sian M Robinson, ${ }^{3,4}$ Cyrus Cooper, $^{3,4,5}$ \\ Keith M Godfrey, 3,4,5 Graham Roberts, 1,2,3 Jane S A Lucas, 1,2 \\ the Southampton Women's Survey Study Group ${ }^{5}$
}

- Additional supplementary tables are published online only. To view these files please visit the journal online (http:// dx.doi.org/10.1136/thoraxjnl2012-202556)

${ }^{1}$ Clinical and Experimental Sciences Academic Unit, University of Southampton Faculty of Medicine, Southampton, UK

${ }^{3}$ Human Development and Health Academic Unit, University of Southampton Faculty of Medicine, Southampton, UK

${ }^{2}$ NIHR Southampton Respiratory Biomedical Research Unit, University of Southampton, Southampton UK

${ }^{4}$ Southampton Medical Research Council Lifecourse Epidemiology Unit, University of Southampton, Southampton UK

${ }^{5}$ NIHR Southampton Biomedical Research Centre, University of Southampton and University Hospital Southampton NHS Foundation Trust, Southampton, UK

\section{Correspondence to} Prof Graham Roberts, Clinical and Experimental Sciences Academic Unit, Mailpoint 803, University of Southampton Faculty of Medicine, Tremona Road, Southampton S016 6YD, UK:

g.c.roberts@soton.ac.uk

Received 10 August 2012

Revised 10 August 2012

Accepted 25 November 2012

Published Online First

3 January 2013

To cite: Pike KC, Inskip HM, Robinson SM, et al. Thorax 2013;68: 372-379.

\section{ABSTRACT}

Background Obesity and asthma have increased in westernised countries. Maternal obesity may increase childhood asthma risk. If this relation is causal, it may be mediated through factors associated with maternal adiposity, such as fetal development, pregnancy complications or infant adiposity. We investigated the relationships of maternal body mass index (BMI) and fat mass with childhood wheeze, and examined the influences of infant weight gain and childhood obesity. Methods Maternal prepregnancy BMI and estimated fat mass (from skinfold thicknesses) were related to asthma, wheeze and atopy in 940 children. Transient or persistent/late wheeze was classified using questionnaire data collected at ages 6, 12, 24 and 36 months and 6 years. At 6 years, skin-prick testing was conducted and exhaled nitric oxide and spirometry measured. Infant adiposity gain was calculated from skinfold thickness at birth and 6 months.

Results Greater maternal BMI and fat mass were associated with increased childhood wheeze (relative risk (RR) 1.08 per $5 \mathrm{~kg} / \mathrm{m}^{2}, \mathrm{p}=0.006$; RR 1.09 per $10 \mathrm{~kg}$, $p=0.003)$; these reflected associations with transient wheeze (RR 1.11, $p=0.003$; RR 1.13, $p=0.002$, respectively), but not with persistent wheeze or asthma. Infant adiposity gain was associated with persistent wheeze, but not significantly. Adjusting for infant adiposity gain or BMI at 3 or 6 years did not reduce the association between maternal adiposity and transient wheeze. Maternal adiposity was not associated with offspring atopy, exhaled nitric oxide, or spirometry. Discussion Greater maternal adiposity is associated with transient wheeze but not asthma or atopy, suggesting effects upon airway structure/function but not allergic predisposition.

\section{INTRODUCTION}

In recent decades, westernised countries have experienced increases in both obesity and respiratory disease, including asthma. These changes may reflect causal links or shared environmental or genetic factors. Increased asthma and asthma-like symptoms have been reported in association with adult $^{1}$ and childhood obesity. ${ }^{2}$ Mechanisms have been proposed attributing this to anatomical, inflammatory or immunological consequences of obesity. $^{34}$ There is evidence that children of obese women are at increased risk of asthma ${ }^{5} 6$ and
Key messages

What is the key question?

- Does maternal body composition influence the presence of asthma and wheeze phenotypes in children at age 6 years?

What is the bottom line?

- This study uses directly measured BMI and estimated maternal fat mass to demonstrate an association between maternal obesity and the transient childhood wheeze phenotype.

Why read on?

- This is the first study to investigate the association of prospectively measured maternal body composition with longitudinal wheeze outcomes in childhood.

wheeze, ${ }^{78}$ suggesting maternal obesity may affect respiratory or immune development.

Maternal prepregnancy weight has increased considerably in recent years, therefore, potential adverse effects upon childhood health represent an important public health issue. ${ }^{9}$ However, socioeconomic and lifestyle factors may confound the relationship between maternal adiposity and childhood wheeze. ${ }^{10}$ Similarly, any such relationship may also be confounded by infant or childhood adiposity since maternal and child obesity are associated, ${ }^{11}$ and associations have been found between childhood obesity and asthma-like symptoms, ${ }^{2}$ between rapid early weight gain and diminished infant lung function, ${ }^{12}$ and between infant adiposity $^{13}$ or weight gain and early childhood wheeze. ${ }^{13}{ }^{14}$ Further possible confounding factors include obesity-associated pregnancy complications, such as preeclampsia, caesarean section, preterm birth and intrauterine growth restriction. ${ }^{10} 15$

Wheeze risk at 18 months has been shown to increase with increasing maternal prepregnancy body mass index (BMI), ${ }^{7}$ the contribution of pregnancy complications to this association was found to be small. Recently, an association between maternal prepregnancy BMI and current asthma in children at age 15-16 years was reported, suggesting that adverse effects of maternal obesity might persist throughout childhood. $^{5}$ Although large, these studies used reported prepregnancy weight, and childhood lung 
function and atopy were not measured. Measures of fat mass may potentially represent maternal adiposity better than BMI. This study is the first to explore the relationship between maternal fat mass and childhood asthma and wheeze alongside objective measurements of atopy and lung function.

\section{METHODS}

\section{Participants}

Participants were mothers and children from the Southampton Women's Survey. ${ }^{16}$ Women aged 20-34 years were recruited during 1998-2002. Women were interviewed and anthropometric measurements made at recruitment, and for those who became pregnant, at 11 and 34 weeks of pregnancy. Childhood follow-up visits occurred at 6,12, 24 and 36 months. During 2006-2010, 1529 children aged 6 years were invited for respiratory follow-up. Home-based questionnaire, skin test and spirometry data were collected from 940 children. Participants were encouraged to attend the clinic for exhaled nitric oxide (eNO) testing; 596 did so, but time and resources meant that not all participants attended. Maternal prepregnancy fat mass and BMI measurements were available for 927 (98.6\%) and 930 (98.9\%) women, respectively (figure 1). Parental consent was obtained and local ethical approval was granted (276/97, 307/97, 089/99, 06/Q1702/104).

\section{Maternal anthropometry}

Prepregnancy height and weight were measured using portable Seca 835 scales (Seca, Birmingham, UK) and Leicester stadiometer (Invicta Plastics, Leicester, UK). Biceps, triceps, suprailiac and subscapular skinfold thicknesses were measured with Harpenden 'John Bull' callipers (British Indicates, St Albans, UK). A standard protocol requiring three readings within $10 \%$ was followed. BMI was calculated as weight $(\mathrm{kg}) /(\text { height }(\mathrm{m}))^{2}$. Fat mass was estimated from body weight and skinfolds using the Durnin and Womersley equation. ${ }^{17}$ Analysis was limited to prepregnancy measurements as body composition equations are not validated in pregnancy.

\section{Childhood anthropometry}

Research nurses measured subscapular skinfold thicknesses at birth and 6 months. Subscapular adiposity change conditional upon initial measurements was calculated using regression to account for exact age and regression to the mean. BMI at 3 and 6 years was calculated from height and weight, and the values converted to age and gender-specific z-scores using the Child Growth Foundation 1990 Reference (London, UK).

\section{Atopy}

Skin-prick testing was conducted at age 6 years using cat, dog, house dust mite (Dermatophagoides pteronyssinus), egg, milk, grass and tree pollen allergens. A positive control of $>3 \mathrm{~mm}$, and negative control of $0 \mathrm{~mm}$ were required. Any response $\geq 3 \mathrm{~mm}$ was considered evidence of atopy.

\section{Childhood asthma and wheeze}

Research nurses administered ISAAC core-questionnaire wheezing-module questions. ${ }^{18}$ Mothers were asked whether their child had 'ever been diagnosed with asthma by a doctor' or had experienced 'any episodes of chestiness associated with wheezing or whistling in his/her chest since they were last seen.' Children who had ever been diagnosed with asthma and had experienced asthma symptoms or received asthma medication within the last year were considered to have current asthma; those reported to wheeze within the last year were considered to have current wheeze. Questionnaire data obtained at 6, 12, 24 and 36 months were combined with that from 6 years to define wheeze phenotypes based upon those of the Tuscon Children's Respiratory Study: ${ }^{19}$

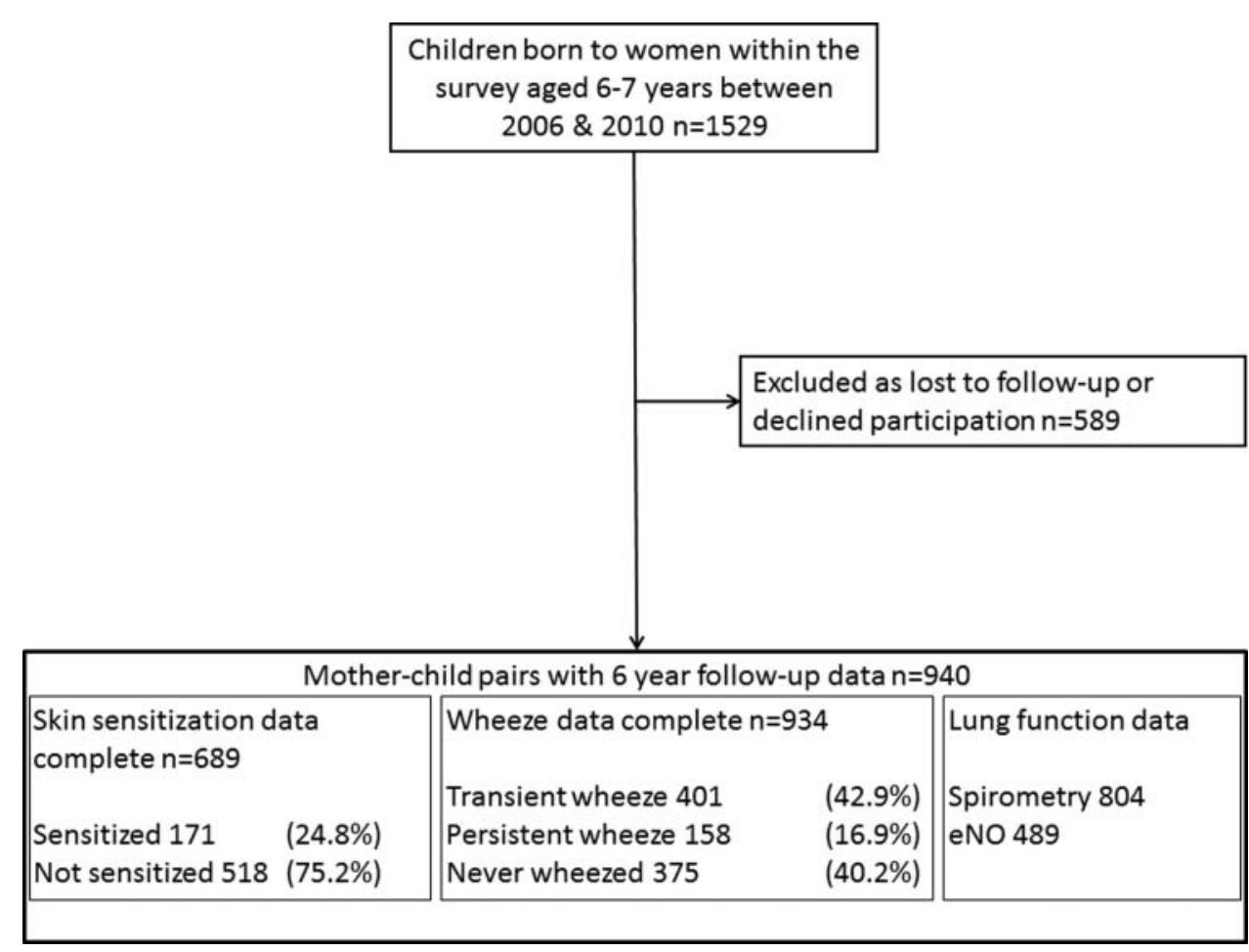

Figure 1 Flow of participants through the study. 
- Transient wheeze: Wheeze $\leq 3$ years but no wheeze or asthma treatment at 6 years.

- Persistent wheeze: Wheeze $\leq 3$ years plus wheeze or asthma treatment at 6 years.

- Late-onset wheeze: No wheeze $\leq 3$ years but wheeze or asthma treatment at 6 years.

Very few children had late-onset wheeze, so the persistent and late-onset wheeze groups were combined.

\section{Lung function}

Spirometry was measured using a portable Koko spirometer with incentive software (KoKo v4; PDS Instrumentation; Louisville, USA). Measurements were made according to American Thoracic Society (ATS) guidelines, ${ }^{20}$ although to avoid discomfort, nose-clips were not worn. Spirometry indices were standardised for height, gender and age using the growing lungs reference. ${ }^{21}$

\section{Exhaled nitric oxide}

eNO Was measured according to European Respiratory Society /ATS recommendations using a NIOX chemiluminescence analyser (Aerocrine, Sweden). ${ }^{22} \mathrm{~A}$ mean of three readings was calculated where possible. Values were normalised by inverse square root transformation then standardised. The sign was reversed so that high standardised scores represent high untransformed eNO values.

\section{Statistical methods}

Relative risks for binary outcomes were modelled using Poisson regression with robust variance; Poisson regression being appropriate for common outcomes where odds ratios cannot be interpreted as relative risks. ${ }^{23}$ Children with transient or persistent/ late wheeze were compared with children who had never wheezed. Linear regression was used for continuous outcomes. Relative risks and regression coefficients were expressed relative to $5 \mathrm{~kg} / \mathrm{m}^{2}$ change in BMI, or $10 \mathrm{~kg}$ change in fat mass. Analyses were also conducted considering maternal BMI as a discrete variable to classify women according to the World Health Organisation scheme as either normal weight (BMI 18.5-24.99), overweight (BMI 25-29.99) or obese (BMI $\geq 30$ ), and considering maternal weight gain in pregnancy according to Institute of Medicine categories.

Potential confounders identified a priori were: maternal age, height, parity, education, socioeconomic status, smoking in pregnancy, asthma, eczema, rhinitis, atopy and child's gender, birth weight, gestation and age at last breastfeed. Potential confounders were tested for association with each respiratory outcome. Model 1 included all variables associated with each outcome, but excluded birth weight, gestation, adiposity gain in the first 6 months of life and the child's BMI at age 6 years, as each of these may lie on the causal pathway. Model 2 included birth weight and gestation if they were significantly associated with the outcomes, and further analyses were conducted adjusting for all significantly associated confounders (including birth weight and gestation) and infant adiposity gain (birth to 6 months) (Model 3) and child's BMI aged 6 years (Model 4).

Based upon effect sizes of approaching 5\% seen in previous studies, we estimated approaching $100 \%$ power to detect an increase in risk of this magnitude per kg maternal fat mass, and of 80-100\% per BMI unit dependent upon physiological outcome. Bonferroni correction was considered over-conservative as the analyses were designed a priori to test a limited number of hypotheses and not all the tests were independent. ${ }^{24}$ We focused our interest on results with $\mathrm{p}$ values $\leq 0.01$ and considered consistency of the findings in our interpretation. Stata 11 (Stata Corp, College Station, Texas, USA) was used for all analyses.

\section{RESULTS \\ Participants}

Participating mothers were similar to non-participants in terms of body composition, asthma and atopy, however, they were slightly older, taller, less likely to smoke in pregnancy, more likely to be primiparous and were of higher educational attainment and social class. Participating children were of similar birth weight and gestation compared with those not followed-up (table 1). When compared with the children attending the clinic, children unable to attend did not differ significantly (data not shown).

The median (IQR) maternal BMI was $24.3(22.0-27.5) \mathrm{kg} / \mathrm{m}^{2}$; $261(28.1 \%)$ mothers were overweight and $135(14.5 \%)$ were obese. Median maternal prepregnancy fat mass was 20.3 (16.3-25.9) kg. The median period between recruitment and 11-week interviews was 67 weeks (32-106 weeks). The mean (SD) difference in BMI calculated from weight measured at 11 weeks' gestation was $0.62(1.62) \mathrm{kg} / \mathrm{m}^{2}$ greater than that calculated from weight measured at recruitment, while BMI calculated from the weight that mothers self-reported at 11 weeks of pregnancy to have been their immediate prepregnancy weight was $0.34(1.78) \mathrm{kg} / \mathrm{m}^{2}$ less than that calculated from weight measured at recruitment; the respective correlation coefficients were 0.95 and 0.93. Both maternal BMI and maternal fat mass were positively associated with a child's birth weight $(p<0.001)$, there was no significant association with infant adiposity change.

Wheeze was experienced by 559 children (59.9\%), and 137 $(14.6 \%)$ had wheeze at age 6 years. Wheezing was transient in $401(42.9 \%)$, and persistent/late in 158 children $(16.9 \%)$ (figure 1). Asthma had been diagnosed in 145 children (15.4\%), of whom $100(10.6 \%)$ had current symptoms or asthma treatment. Technically acceptable spirometry was achieved by 804 children $(85.5 \%) ; 489(82.0 \%)$ of 596 children attending the clinic had acceptable eNO measurements (figure 1).

\section{Childhood wheeze}

Maternal prepregnancy fat mass was positively associated with ever wheezing (RR 1.09 per $10 \mathrm{~kg}, \mathrm{p}=0.003$ ). This association remained after adjusting for potential confounders (RR 1.08 per $10 \mathrm{~kg}, \mathrm{p}=0.007-$ Model 1, basic confounders); results were similar when gestation, infant adiposity gain or child's BMI, aged 6 years, were included in the model (table 2). Maternal fat mass was not associated with current or ever asthma. Children experiencing wheeze $\leq 3$ years appeared to account for most of the association between maternal fatness and ever wheezing, as maternal fat mass was positively associated with transient wheeze (RR 1.13, $\mathrm{p}=0.002$ ), but not with current or persistent wheeze. The association with transient wheeze remained after adjusting for potential confounders, gestation, infant adiposity gain and child's BMI aged 6 years (table 2, Models 1-4), and also when child's BMI aged 3 years was adjusted for (RR 1.01, $\mathrm{p}=0.02$ ).

Similar associations were found between maternal prepregnancy BMI and wheeze outcomes (table 3). Maternal BMI was positively associated with ever wheezing (RR 1.08 per $5 \mathrm{~kg} / \mathrm{m}^{2}$, $\mathrm{p}=0.006)$ and transient wheeze (RR 1.11 per $5 \mathrm{~kg} / \mathrm{m}^{2}$, $\mathrm{p}=0.003)$. These associations remained in each of the four adjusted models. Maternal BMI was not associated with ever or current asthma, current or persistent wheeze. 
Table 1 Comparison of Southampton Women's Survey mother-child pairs with complete data with those lacking either maternal body composition or 6-year follow-up data, but born in the same time period

\begin{tabular}{|c|c|c|c|}
\hline & $\begin{array}{l}\text { Participating } \\
\text { mother-child } \\
\text { pairs }(n=940)\end{array}$ & $\begin{array}{l}\text { Mother-child } \\
\text { pairs with } \\
\text { missing data } \\
(n=589)\end{array}$ & $p$ Value \\
\hline \multicolumn{4}{|l|}{ Maternal characteristics } \\
\hline $\begin{array}{l}\text { Age at child's birth, } \\
\text { years (mean (SD)) }\end{array}$ & $30.3(3.8)$ & $29.7(3.8)$ & 0.007 \\
\hline \multicolumn{4}{|l|}{ Primiparous (n (\%)) } \\
\hline No & $494(52.6)$ & $355(60.3)$ & 0.003 \\
\hline Yes & $446(47.5)$ & $234(39.7)$ & \\
\hline \multicolumn{4}{|l|}{ Qualifications (n (\%)) } \\
\hline None & $15(1.6)$ & $36(6.1)$ & $<0.001$ \\
\hline GCSE D-G & $88(9.4)$ & $67(11.4)$ & \\
\hline GCSE $A^{*}-C$ & $278(29.6)$ & $165(28.1)$ & \\
\hline A level & $270(28.8)$ & $175(29.8)$ & \\
\hline HND & $66(7.0)$ & $39(6.6)$ & \\
\hline Degree & $222(23.6)$ & $106(18.0)$ & \\
\hline \multicolumn{4}{|l|}{ Parents' social class (n (\%)) } \\
\hline 1 & $100(10.8)$ & $52(12.3)$ & 0.019 \\
\hline ॥ & $454(48.8)$ & $178(42.3)$ & \\
\hline IIIN & $263(28.5)$ & $112(26.6)$ & \\
\hline IIIM & $72(7.7)$ & $51(12.1)$ & \\
\hline IV & $39(4.2)$ & $20(4.8)$ & \\
\hline V & $2(0.2)$ & $8(1.9)$ & \\
\hline \multicolumn{4}{|c|}{ Smoked in pregnancy $(\mathrm{n}(\%))$} \\
\hline No & $768(84.9)$ & $431(77.2)$ & $<0.001$ \\
\hline Yes & $137(15.1)$ & $127(22.8)$ & \\
\hline \multicolumn{4}{|l|}{ Maternal asthma (n (\%)) } \\
\hline No & $733(78.7)$ & $442(76.2)$ & 0.251 \\
\hline Yes & $198(21.3)$ & $138(23.8)$ & \\
\hline \multicolumn{4}{|c|}{ Maternal childhood eczema (n (\%)) } \\
\hline No & $758(81.5)$ & $476(82.1)$ & 0.783 \\
\hline Yes & $172(18.5)$ & $104(17.9)$ & \\
\hline \multicolumn{4}{|l|}{ Maternal rhinitis (n (\%)) } \\
\hline No & 539 (57.9) & $353(60.9)$ & 0.254 \\
\hline Yes & $392(42.1)$ & $227(39.1)$ & \\
\hline \multicolumn{4}{|l|}{ Maternal atopy (n (\%)) } \\
\hline No & $438(53.0)$ & $236(57.0)$ & 0.185 \\
\hline Yes & $388(47.0)$ & $178(43.0)$ & \\
\hline Height, cm (mean (SD)) & $163.5(6.6)$ & $162.7(6.0)$ & 0.020 \\
\hline $\begin{array}{l}\mathrm{BMI}, \mathrm{kg} / \mathrm{m}^{2} \text { (median, } \\
(\mathrm{IQR}))\end{array}$ & $24.3(22.0-27.5)$ & $24.1(21.8-27.4)$ & 0.657 \\
\hline $\begin{array}{l}\text { Fat mass, kg (median, } \\
(\text { IQR)) }\end{array}$ & $20.3(16.3-25.9)$ & $19.5(15.7-25.8)$ & 0.116 \\
\hline \multicolumn{4}{|l|}{ Child's characteristics } \\
\hline \multicolumn{4}{|l|}{ Gender (n (\%)) } \\
\hline Male & $485(51.6)$ & $313(53.4)$ & 0.489 \\
\hline Female & $455(48.4)$ & $273(46.6)$ & \\
\hline $\begin{array}{l}\text { Birth weight, } \mathrm{kg} \text { (mean } \\
\text { (SD)) }\end{array}$ & $3.440(0.551)$ & $3.420(0.580)$ & 0.615 \\
\hline $\begin{array}{l}\text { Gestational age, weeks } \\
\text { (median (IQR)) }\end{array}$ & $40.1(39.0-41.0)$ & $40.0(39.1-41.0)$ & 0.969 \\
\hline \multicolumn{4}{|c|}{ Mother smoked during child's infancy (n (\%)) } \\
\hline No & $768(84.9)$ & $431(77.2)$ & $<0.001$ \\
\hline Yes & $137(15.1)$ & $125(22.8)$ & \\
\hline
\end{tabular}

Maternal weight gain was not associated with respiratory outcome in the children (see online supplementary tables S1 and S2).

\section{Childhood atopy}

Neither maternal fat mass (table 2) nor BMI (table 3) were associated with cutaneous sensitisation, before or after adjusting for confounders.

\section{Lung function and eNO}

Neither maternal fat mass nor BMI were associated with any measure of lung function, (table 4). There were no associations after adjusting for confounders in any multivariable model. No associations, before or after adjustment, were found between either maternal fat mass or maternal BMI and eNO (see online supplementary table S3).

All the above results for wheeze, atopy, lung function and eNO were unchanged by considering BMI as a categorical variable, or by limiting the analysis to women who became pregnant within 1 year of their initial interview.

\section{Infant adiposity gain}

Infant adiposity gain was associated with persistent wheeze, but significance was reduced after adjusting for likely confounders (RR 1.14, $\mathrm{p}=0.05)$. Similar results were seen after other potential confounders were adjusted for: gestation (RR 1.14, $\mathrm{p}=0.04$ -Model 2), BMI aged 3 years (RR 1.10, $\mathrm{p}=0.16$-Model 3) and BMI aged 6 years (RR 1.14, $\mathrm{p}=0.05$-Model 4). There were no significant associations with ever or current asthma, or ever or current wheeze. By contrast with the findings for maternal obesity, no association was found between infant adiposity gain and transient wheeze (see online supplementary table S4). There were weak inverse associations between infant adiposity gain and both $\mathrm{FEF}_{25-75 \%}$ and $\mathrm{FEV}_{1} /$ forced vital capacity (FVC) $(p=0.02$ for each) (see online supplementary table S5).

\section{DISCUSSION}

This is the first study to measure the association between prepregnancy measurements of maternal adiposity and longitudinal childhood wheeze phenotypes. Greater maternal fat mass and BMI were associated with increased childhood wheeze risk. There were significant positive associations with transient wheeze, but none with persistent wheeze or asthma. This has potentially important public health implications, since individuals who wheeze in infancy more commonly develop chronic obstructive airways disease as adults. Adjusting for infant adiposity or child's BMI at age 3 or 6 years did not reduce the association with transient wheeze. There were no associations between maternal fatness and atopy, eNO or spirometry.

Previous studies have used BMI to estimate adiposity. Women were recruited after conception and prepregnancy weight, often self-reported several months after birth ${ }^{6}$; in some studies, neither height nor weight were measured. ${ }^{7}$ To provide an objective measure of adiposity uncomplicated by variation in BMI with body type, ${ }^{25}$ or by alterations in fat distribution during pregnancy, ${ }^{26}$ we estimated maternal fat mass from prepregnancy skinfold thicknesses. BMI calculated from weight measured prepregnancy, and from estimated prepregnancy weight self-reported at 11 weeks of pregnancy were closely correlated. Moreover, the study's main findings were unchanged by restricting analyses to women for whom less than a year had elapsed between initial and pregnancy interviews. Together, these findings suggest that the measured prepregnancy values 
Table 2 Relationship between maternal prepregnancy fat mass $(\mathrm{kg})$ and wheeze and atopy phenotypes in the offspring at age 6 years

\begin{tabular}{|c|c|c|c|c|c|c|c|c|c|c|c|c|}
\hline \multirow[b]{2}{*}{ Outcome } & \multicolumn{4}{|c|}{ Unadjusted analysis } & \multicolumn{4}{|c|}{ Model 1} & \multicolumn{4}{|c|}{ Model 2} \\
\hline & $\mathbf{R R}$ & $(95 \% \mathrm{Cl})$ & $\mathrm{p}$ Value & $\mathbf{n}$ & RR & $(95 \% \mathrm{Cl})$ & $p$ Value & $\mathbf{n}$ & RR & $(95 \% \mathrm{Cl})$ & $p$ Value & $\mathrm{n}$ \\
\hline Ever wheeze & 1.09 & (1.03 to 1.16$)$ & 0.003 & 921 & 1.08 & (1.02 to 1.15$)$ & 0.007 & 895 & 1.09 & (1.03 to 1.16$)$ & 0.002 & 895 \\
\hline Ever asthma & 1.10 & (0.93 to 1.31$)$ & 0.27 & 927 & 1.05 & (0.89 to 1.24$)$ & 0.57 & 890 & 1.10 & (0.93 to 1.30$)$ & 0.28 & 890 \\
\hline Current wheeze & 1.04 & (0.86 to 1.25$)$ & 0.68 & 927 & 1.06 & (0.87 to 1.29$)$ & 0.54 & 808 & 1.09 & (0.90 to 1.32 ) & 0.39 & 808 \\
\hline Current asthma & 1.14 & (0.91 to 1.43 ) & 0.24 & 927 & 1.10 & (0.89 to 1.37 ) & 0.39 & 918 & 1.14 & (0.92 to 1.41$)$ & 0.22 & 918 \\
\hline Transient wheeze & 1.13 & (1.05 to 1.23 ) & 0.002 & 764 & 1.11 & (1.02 to 1.20$)$ & 0.01 & 743 & 1.12 & (1.03 to 1.21$)$ & 0.006 & 743 \\
\hline Persistent wheeze & 1.12 & (0.96 to 1.30$)$ & 0.14 & 526 & 1.08 & (0.94 to 1.24$)$ & 0.26 & 519 & 1.11 & (0.98 to 1.27 ) & 0.11 & 519 \\
\hline \multirow[t]{2}{*}{ Atopy } & 1.07 & (0.91 to 1.25$)$ & 0.43 & 681 & 1.14 & (0.97 to 1.35$)$ & 0.12 & 590 & 1.14 & (0.97 to 1.35$)$ & 0.12 & 590 \\
\hline & & & & & \multicolumn{4}{|c|}{ Model 3} & \multicolumn{4}{|c|}{ Model 4} \\
\hline Ever wheeze & & & & & 1.1 & (1.03 to 1.17$)$ & 0.004 & 817 & 1.09 & (1.03 to 1.15 ) & 0.004 & 893 \\
\hline Ever asthma & & & & & 1.14 & (0.96 to 1.35$)$ & 0.13 & 823 & 1.06 & (0.89 to 1.28 ) & 0.52 & 888 \\
\hline Current wheeze & & & & & 1.03 & (0.84 to 1.28$)$ & 0.76 & 741 & 1.09 & (0.89 to 1.33 ) & 0.40 & 806 \\
\hline Current asthma & & & & & 1.17 & (0.94 to 1.45 ) & 0.16 & 835 & 1.14 & (0.91 to 1.42 ) & 0.27 & 915 \\
\hline Transient wheeze & & & & & 1.11 & (1.02 to 1.21$)$ & 0.01 & 686 & 1.11 & (1.02 to 1.20$)$ & 0.01 & 741 \\
\hline Persistent wheeze & & & & & 1.12 & (0.97 to 1.30$)$ & 0.13 & 478 & 1.10 & (0.96 to 1.27$)$ & 0.17 & 519 \\
\hline Atopy & & & & & 1.21 & (1.02 to 1.44$)$ & 0.03 & 546 & 1.15 & (0.97 to 1.36$)$ & 0.12 & 590 \\
\hline
\end{tabular}

Relative risk represents change in outcome per $10 \mathrm{~kg}$ of maternal prepregnancy fat mass.
Model 1 Adjusted for potential confounders significantly associated with the outcome, excluding child's birth weight and gestation

Model 1 Adjusted for potential confounders significantly associated with the outcome, excluding child's birth weight and gestation. Current wheeze-maternal education, asthma and atopy; Current asthma-maternal education and asthma; Transient wheeze-maternal height, parity, asthma and rhinitis, child's gender and age last breast fed; Persistent wheeze-maternal education, asthma and rhinitis and child's gender; Atopy-maternal social class, asthma and atopy, and child's gender.

Model 2 adjusted for potential confounders significantly associated with the outcome, including child's birth weight and gestation.

Ever wheeze-maternal education, asthma and rhinitis, child's gender, age last breast fed and gestation; Ever asthma-maternal education, asthma, smoking in pregnancy and parity, child's gender and gestation; Current wheeze-maternal education, asthma and atopy, child's gender and gestation; Current asthma-maternal education and asthma, and child's gestation; Transient wheeze-maternal height, parity, asthma and rhinitis, child's gender, age last breast fed and gestation; Persistent wheeze-maternal education, asthma and rhinitis, child's gender and gestation; Atopy-maternal social class, asthma and atopy, and child's gender.

Model 3 adjusted for increase in adiposity between birth and 6 months and potential confounders significantly associated with the outcome (listed in Model 2) including child's birth weight and gestation.

Model 4 adjusted for child's BMI at age 6 years and potential confounders significantly associated with the outcome including child's birth weight and gestation.

BMI, body mass index.

are likely to accurately reflect relative maternal fatness immediately before and during early pregnancy.

The finding of increased wheeze in association with greater maternal adiposity is consistent with previous studies. Associations have been found between higher maternal BMI and increased wheeze at 18 months, ${ }^{7} 3$ years ${ }^{8} 27$ and 8 years, ${ }^{6}$ and also in adolescence. ${ }^{5}$

Few studies have assessed objective measures of atopy in relation to maternal adiposity. Kumar $e t \mathrm{al}^{8}$ found an inverse relationship between maternal prepregnancy BMI and cord blood total IgE, but no association with food allergy or eczema, while Scholtens $e t a l^{6}$ found no association with specific IgE to inhalant allergens. We have found neither an association between maternal adiposity and cutaneous sensitisation, nor eosinophilic airway inflammation measured by eNO. Furthermore, although cross-sectional adult data have suggested an association between adiposity and atopy, ${ }^{28}$ cross-sectional studies in childhood provide no evidence for this. ${ }^{29}$

The positive association between maternal adiposity and transient wheeze is unique to this study, as no other study has assessed longitudinal wheeze phenotypes. Our finding is supported by studies assessing wheeze in early childhood. ${ }^{78} 27$ The lack of longitudinal studies means that evidence supporting an association between maternal adiposity and persistence of wheeze symptoms in older children is less conclusive. No association was found between maternal adiposity and doctordiagnosed asthma in our study, although our power was less for this outcome than for transient or for ever wheeze. The only study to date to have found such an association, did so in infancy when asthma is difficult to diagnose. ${ }^{27}$ Two studies ${ }^{5} 6$ have reported associations with self-reported asthma, although only after considering effect modification by genetic predisposition. However, these studies' results were contradictory; Scholtens found maternal adiposity associated with asthma only in children considered predisposed due to parental asthma or allergy, ${ }^{6}$ while Patel found this association to be strongest in children without a parental history of atopy. ${ }^{5}$ Subtle differences in the phenotypic characteristics of the individuals assigned to the current wheeze grouping may have existed between the populations and age groups considered in each of these studies. Similarly, differences in the nature and extent of residual confounding associated with the measured or estimated values of maternal adiposity used may explain, in part, the conflicting results.

Previous studies report an effect of maternal adiposity beyond that mediated by pregnancy or birth complications, ${ }^{7}$ while this and other studies suggest that a direct effect beyond that of an association with childhood obesity is possible. We were unable to confirm our previous finding of increased wheeze risk in association with greater infant adiposity gain, ${ }^{13}$ possibly due to reduced power, as fewer children were seen at 6 than at 3 years. Nevertheless, it was felt important to correct for potential confounding by infant adiposity gain. Adjustment for infant adiposity gain or childhood BMI did not reduce the association between maternal adiposity and transient wheeze, suggesting that the effect of maternal obesity is not mediated by childhood adiposity. Indeed, the contrasting findings of an association between maternal obesity and transient wheeze, and a borderline association between infant weight gain and persistent wheeze, suggests separate mechanisms may underlie these associations.

This study did not detect any association between maternal pregnancy weight gain, according to Institute of Medicine categorisation, and any wheeze, atopy or lung function outcome. 
Table 3 Relationship between maternal prepregnancy BMI and wheeze and atopy phenotypes in the offspring at age 6 years

\begin{tabular}{|c|c|c|c|c|c|c|c|c|c|c|c|c|}
\hline \multirow[b]{2}{*}{ Outcome } & \multicolumn{4}{|c|}{ Unadjusted analysis } & \multicolumn{4}{|c|}{ Model 1} & \multicolumn{4}{|c|}{ Model 2} \\
\hline & $\mathbf{R R}$ & $(95 \% \mathrm{Cl})$ & $\mathrm{p}$ Value & N & RR & $(95 \% \mathrm{Cl})$ & $p$ Value & $\mathbf{n}$ & RR & $(95 \% \mathrm{Cl})$ & $p$ Value & $\mathbf{n}$ \\
\hline Ever wheeze & 1.08 & (1.02 to 1.14$)$ & 0.006 & 924 & 1.07 & (1.01 to 1.12$)$ & 0.01 & 897 & 1.08 & (1.02 to 1.13 ) & 0.004 & 897 \\
\hline Ever asthma & 1.07 & (0.92 to 1.24$)$ & 0.4 & 930 & 1.02 & (0.87 to 1.18$)$ & 0.84 & 892 & 1.06 & (0.91 to 1.24 ) & 0.44 & 892 \\
\hline Current wheeze & 0.99 & (0.85 to 1.16$)$ & 0.94 & 930 & 0.99 & (0.84 to 1.17 ) & 0.94 & 809 & 1.02 & (0.87 to 1.20$)$ & 0.79 & 809 \\
\hline Current asthma & 1.10 & (0.91 to 1.33 ) & 0.31 & 930 & 1.06 & (0.88 to 1.27 ) & 0.53 & 920 & 1.10 & (0.92 to 1.32 ) & 0.30 & 920 \\
\hline Transient wheeze & 1.11 & (1.04 to 1.18 ) & 0.003 & 767 & 1.10 & (1.03 to 1.17 ) & 0.006 & 746 & 1.11 & (1.04 to 1.18$)$ & 0.002 & 746 \\
\hline Persistent wheeze & 1.08 & (0.95 to 1.24$)$ & 0.22 & 527 & 1.05 & (0.93 to 1.20$)$ & 0.42 & 519 & 1.09 & (0.97 to 1.24 ) & 0.16 & 519 \\
\hline \multirow[t]{2}{*}{ Atopy } & 1.08 & (0.94 to 1.24$)$ & 0.31 & 681 & 1.13 & (0.98 to 1.31 ) & 0.10 & 589 & 1.13 & (0.98 to 1.31$)$ & 0.1 & 589 \\
\hline & & & & & Model 3 & & & & Mode & & & \\
\hline Ever wheeze & & & & & 1.08 & (1.02 to 1.14$)$ & 0.009 & 819 & 1.07 & (1.02 to 1.13 ) & 0.01 & 895 \\
\hline Ever asthma & & & & & 1.08 & (0.92 to 1.26$)$ & 0.34 & 825 & 1.02 & (0.86 to 1.20$)$ & 0.85 & 890 \\
\hline Current wheeze & & & & & 0.97 & (0.82 to 1.16$)$ & 0.77 & 742 & 1.02 & (0.86 to 1.22 ) & 0.79 & 807 \\
\hline Current asthma & & & & & 1.10 & (0.91 to 1.33 ) & 0.31 & 837 & 1.10 & (0.90 to 1.34 ) & 0.35 & 917 \\
\hline Transient wheeze & & & & & 1.10 & (1.03 to 1.18$)$ & 0.006 & 689 & 1.10 & (1.03 to 1.18 ) & 0.007 & 744 \\
\hline Persistent wheeze & & & & & 1.09 & (0.95 to 1.25 ) & 0.23 & 478 & 1.08 & (0.95 to 1.23 ) & 0.25 & 519 \\
\hline Atopy & & & & & 1.17 & (1.00 to 1.36$)$ & 0.05 & 545 & 1.14 & (0.98 to 1.32 ) & 0.09 & 589 \\
\hline
\end{tabular}

Relative risk represents change in outcome per $5 \mathrm{~kg} / \mathrm{m}^{2}$ of maternal prepregnancy BMI.

Models 1-4 adjusted for confounders as described in table 2.

BMI, body mass index.

This is surprising given that excessive pregnancy weight gain has been shown to be associated with infant adiposity, and has been proposed to predispose to a number of obesity-associated adverse outcomes. ${ }^{30}$ Possibly, categorisation according to weight gain throughout pregnancy is not sensitive to the effects of weight gain during periods of particular significance for determining fetal health and development. Alternatively, absolute maternal fatness may determine fetal exposure and childhood outcome more directly than rate of weight gain. Serum levels of proinflammatory cytokines are known to be higher in obese pregnant women than pregnant women of normal weight, ${ }^{31}$ and it has been proposed that an increased inflammatory response might affect fetal immunological or pulmonary development. Other factors associated with obesity include high glucose, insulin, lipid and leptin levels. ${ }^{4} 32$ Although observational studies cannot determine causality, careful characterisation of wheeze phenotypes may suggest mechanisms by which maternal adiposity might predispose to childhood wheeze. In the absence of an association with atopy, there is little to support an effect of maternal adiposity upon atopic immunity.

Transient childhood wheeze is believed to arise during viral infections in individuals predisposed to airways obstruction. It is possible that maternal obesity might affect airway development. Leptin is elevated in obesity, ${ }^{32}$ and leptin receptors in the lung may mediate effects upon lung growth. ${ }^{33}$ However, although lung function is believed to track across the life-course, no

Table 4 Relationship between maternal prepregnancy fat mass $(\mathrm{kg})$ and exhaled nitric oxide and lung function in the offspring at age 6 years

\begin{tabular}{|c|c|c|c|c|c|c|c|c|c|c|c|c|}
\hline & \multicolumn{4}{|c|}{ Unadjusted analysis } & \multicolumn{4}{|l|}{ Model 1} & \multicolumn{4}{|l|}{ Model 2} \\
\hline & Beta & (95\% Cl) & $p$ Value & $\mathbf{n}$ & $\boldsymbol{\beta}$ & $(95 \% \mathrm{Cl})$ & $p$ Value & $\mathbf{n}$ & $\boldsymbol{\beta}$ & (95\% Cl) & $\mathrm{p}$ Value & $\mathrm{n}$ \\
\hline $\mathrm{FEV}_{1} \mathrm{z}$-score & 0.0349 & $(-0.0413$ to 0.1111$)$ & 0.37 & 793 & 0.0274 & $(-0.0476$ to 0.1025$)$ & 0.47 & 793 & 0.0230 & $(-0.0555$ to 0.1015$)$ & 0.56 & 784 \\
\hline FVC $z$-score & 0.0433 & $(-0.0439$ to 0.1306$)$ & 0.33 & 793 & 0.0301 & $(-0.0586$ to 0.1188$)$ & 0.5 & 765 & 0.0301 & ( -0.0586 to 0.1188 ) & 0.5 & 765 \\
\hline $\mathrm{FEF}_{25-75 \%} \mathrm{z}$-score & 0.0163 & $(-0.0796$ to 0.1122$)$ & 0.74 & 793 & 0.0181 & $(-0.0775$ to 0.1137$)$ & 0.71 & 793 & 0.0071 & $(-0.0886$ to 0.1028$)$ & 0.88 & 793 \\
\hline $\mathrm{FEV}_{1} / \mathrm{FVC}$ z-score & -0.0190 & $(-0.1043$ to 0.0663$)$ & 0.66 & 793 & -0.0130 & ( -0.0998 to 0.0739$)$ & 0.77 & 765 & -0.0130 & $(-0.0998$ to 0.0739$)$ & 0.77 & 765 \\
\hline \multirow[t]{2}{*}{ Exhaled nitric oxide } & -0.0575 & ( -0.1667 to 0.0517$)$ & 0.30 & 482 & -0.0908 & $(-0.2018$ to 0.0203$)$ & 0.11 & 477 & -0.0908 & ( -0.2018 to 0.0203$)$ & 0.11 & 477 \\
\hline & & & & & Model 3 & & & & Model 4 & & & \\
\hline $\mathrm{FEV}_{1} \mathrm{z}$-score & & & & & 0.0115 & $(-0.0702$ to 0.0932$)$ & 0.78 & 721 & 0.0122 & ( -0.0684 to 0.0928$)$ & 0.76 & 784 \\
\hline FVC z-score & & & & & 0.0287 & $(-0.0625$ to 0.1199$)$ & 0.54 & 713 & 0.0001 & $(-0.0913$ to 0.0916$)$ & 0.99 & 765 \\
\hline $\mathrm{FEF}_{25-75 \%} \mathrm{z}$-score & & & & & -0.0035 & $(-0.1031$ to 0.0961$)$ & 0.94 & 725 & 0.0160 & ( -0.0829 to 0.1149$)$ & 0.75 & 793 \\
\hline $\mathrm{FEV}_{1} / \mathrm{FVC}$ z-score & & & & & -0.0293 & (-0.1181 to 0.0594$)$ & 0.51 & 713 & 0.0055 & $(-0.0846$ to 0.0956$)$ & 0.9 & 765 \\
\hline Exhaled nitric oxide & & & & & -0.0989 & $(-0.2152$ to 0.0174$)$ & 0.09 & 434 & -0.0889 & $(-0.2029$ to 0.0250$)$ & 0.12 & 477 \\
\hline
\end{tabular}

Regression coefficient represents change in outcome per $10 \mathrm{~kg}$ of maternal prepregnancy fat mass.

Model 1 Adjusted for potential confounders significantly associated with the outcome, excluding child's birth weight and gestation.

$\mathrm{FEV}_{1}$-child's gender; FVC-maternal smoking in pregnancy and rhinitis, and child's gender; FEF $_{25-75 \%}$-maternal parity and child's gender; FEV 1 /FVC-maternal rhinitis, eczema, smoking in pregnancy and parity; eNO-maternal height, asthma and eczema.

Model 2 adjusted for potential confounders significantly associated with the outcome, including child's birth weight and gestation.

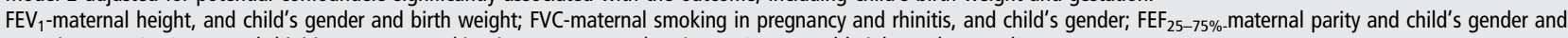
gestation; FEV $/$ FVC-maternal rhinitis, eczema, smoking in pregnancy and parity; eNO-maternal height, asthma and eczema.

Model 3 adjusted for increase in adiposity between birth and 6 months and potential confounders significantly associated with the outcome including child's birth weight and gestation (listed in Model 2).

Model 4 adjusted for child's BMI at age 6 years and potential confounders significantly associated with the outcome including child's birth weight and gestation (listed in Model 2). BMI, body mass index. 
association was found between maternal adiposity and spirometry at 6 years. This may reflect a transient effect upon lung function, or there may be subtle differences in airway function that the spirometric indices measured could not detect. It is possible that lung function effects are particularly important in the transient wheeze phenotype, and that a significant association may be found in a cohort large enough to support analysis of the relationship between adiposity and lung function stratified by wheeze phenotype. Alternatively, maternal adiposity may confer vulnerability to transient wheeze via an effect upon severity of viral infection, perhaps by an effect upon innate immunity similar to that proposed to explain reported associations between prenatal vitamin D exposure and childhood wheeze. ${ }^{34}$ Certainly, there is data to support increased respiratory infection in overweight individuals. ${ }^{35}$

This study's strength lies in the robust measurement of maternal fat mass and BMI in a longitudinal birth cohort. The wheeze outcomes were assessed using standardised questions permitting comparison with other studies. Uniquely, this study considered the influence of early infant adiposity gain upon outcome, and also objectively assessed lung function and skin sensitisation. Although observational studies are inherently vulnerable to response bias, the response rate was good in this study, and neither maternal prepregnancy fat mass nor BMI differed significantly between participants and non-participants. Furthermore, the relationship between maternal adiposity and childhood wheeze was one of many objectives of a broader study assessing the effect of maternal nutrition upon childhood growth and health, it is unlikely that parental health knowledge may have affected participation. A hurdle to interpreting the data surrounds identifying the relevant exposure. Ideally, measurements might be taken in early pregnancy rather than in prepregnancy, but changes to maternal body composition vary between women, and there are no standardised measurements or reference charts for pregnancy. Critical windows in pregnancy may also be relevant. Despite these challenges, we find that the association with wheeze holds whether measuring BMI or adiposity estimated from skin fold thickness prior to pregnancy.

In conclusion, we found that greater maternal prepregnancy fat mass and BMI were associated with an increased risk of transient wheeze in childhood. There was no evidence for an effect of maternal adiposity upon childhood atopy, but the association with transient wheeze suggests an effect upon airway development.

Acknowledgements The research was supported by infrastructure provided by the NIHR Southampton Respiratory Biomedical Research Unit and the NIHR

Southampton Biomedical Research Centre. Clinical investigations were conducted in Southampton Wellcome Trust Clinical Research Facility.

Contributors JSAL, KMG, HMI, CC, SMR and GCR designed research; KCP and JSAL conducted research; HI and KCP analysed data; KCP and JSAL, wrote the first draft of the paper; JSAL had primary responsibility for final content. All authors read and approved the final manuscript.

\section{Competing interests None.}

Ethics approval Southampton and South West Hampshire Local Research Ethics Committee.

\section{Provenance and peer review Not commissioned; externally peer reviewed}

Data sharing statement The Southampton Women's Survey is a complex study with ongoing data collection of many of the waves of the study. We encourage data sharing through collaboration, wherever possible, to maximise the use of the study data. In the first instance, enquiries should be made to the MRC Lifecourse Epidemiology Unit Director, Professor Cyrus Cooper on cc@mrc.soton.ac.uk.

\section{REFERENCES}

1 Camargo CA Jr, Weiss ST, Zhang S, et al. Prospective study of body mass index, weight change, and risk of adult-onset asthma in women. Arch Intern Med 1999:159:2582-8.
2 Castro-Rodriguez JA, Holberg CJ, Morgan WJ, et al. Increased incidence of asthmalike symptoms in girls who become overweight or obese during the school years. Am J Respir Crit Care Med 2001;163:1344-9.

3 Gunnbjornsdottir MI, Omenaas E, Gislason T, et al. Obesity and nocturnal gastro-oesophageal reflux are related to onset of asthma and respiratory symptoms. Eur Respir J 2004;24:116-21

4 Ramsay JE, Ferrell WR, Crawford L, et al. Maternal obesity is associated with dysregulation of metabolic, vascular, and inflammatory pathways. J Clin Endocrinol Metab 2002:87:4231-7.

5 Patel SP, Rodriguez A, Little MP, et al. Associations between pre-pregnancy obesity and asthma symptoms in adolescents. J Epidemiol Community Health 2012:66:809-14.

6 Scholtens S, Wijga AH, Brunekreef B, et al. Maternal overweight before pregnancy and asthma in offspring followed for 8 years. Int I Obes (Lond) 2010;34:606-13.

7 Haberg SE, Stigum H, London SJ, et al. Maternal obesity in pregnancy and respiratory health in early childhood. Paediatr Perinat Epidemiol 2009;23:352-62.

8 Kumar R, Story RE, Pongracic JA, et al. Maternal pre-pregnancy obesity and recurrent wheezing in early childhood. Pediatr Allergy Immunol Pulmonol 2010;23:183-90.

9 Flegal $\mathrm{KM}$, Carroll MD, Ogden $\mathrm{CL}$, et al. Prevalence and trends in obesity among US adults, 1999-2008. JAMA 2010;303:235-41.

10 Kumari AS. Pregnancy outcome in women with morbid obesity. Int J Gynaecol Obstet 2001;73:101-7.

11 Whitaker RC. Predicting preschooler obesity at birth: the role of maternal obesity in early pregnancy. Pediatrics 2004;114:e29-36

12 Lucas JS, Inskip HM, Godfrey KM, et al. Small size at birth and greater postnatal weight gain: relationships to diminished infant lung function. Am J Respir Crit Care Med 2004:170:534-40.

13 Pike KC, Crozier SR, Lucas JS, et al. Patterns of fetal and infant growth are related to atopy and wheezing disorders at age 3 years. Thorax 2010;65:1099-106

14 Sonnenschein-van der Voort AM, Jaddoe VW, Raat $H$, et al. Fetal and infant growth and asthma symptoms in preschool children: the Generation R Study. Am J Respir Crit Care Med 2012;185:731-7.

15 Raatikainen K, Heiskanen N, Heinonen S. Transition from overweight to obesity worsens pregnancy outcome in a BMI-dependent manner. Obesity (Silver Spring) 2006;14:165-71.

16 Inskip HM, Godfrey KM, Robinson SM, et al. Cohort profile: The Southampton Women's Survey. Int J Epidemiol 2006;35:42-8.

17 Durnin JV, Womersley J. Body fat assessed from total body density and its estimation from skinfold thickness: measurements on 481 men and women aged from 16 to 72 years. Br J Nutr 1974;32:77-97.

18 Asher MI, Keil U, Anderson HR, et al. International Study of Asthma and Allergies in Childhood (ISAAC): rationale and methods. Eur Respir J 1995;8:483-91.

19 Martinez FD, Wright AL, Taussig LM, et al. Asthma and wheezing in the first six years of life. The Group Health Medical Associates. N Engl J Med 1995;332:133-8.

20 Beydon N, Davis SD, Lombardi E, et al., American Thoracic Society/European Respiratory Society Working Group on Infant and Young Children Pulmonary Function Testing. An official American Thoracic Society/European Respiratory Society statement: pulmonary function testing in preschool children. Am J Respir Crit Care Med 2007;175:1304-45

21 Stanojevic S, Wade A, Stocks J, et al. Reference ranges for spirometry across all ages: a new approach. Am J Respir Crit Care Med 2008;177:253-60

22 American Thoracic Society, European Respiratory Society. ATS/ERS recommendations for standardized procedures for the online and offline measurement of exhaled lower respiratory nitric oxide and nasal nitric oxide. Am J Respir Crit Care Med 2005; 171:912-30.

23 Barros $\mathrm{AH}$, Alternatives for logistic regression in cross-sectional studies: an empirical comparison of models that directly estimate the prevalence ratio. Alternatives for logistic regression in cross-sectional studies: an empirical comparison of models that directly estimate the prevalence ratio. BMC Med Res Methodol 2003;3:21.

24 Bland M. An introduction to statistics. Oxford: Oxford University Press, 2000.

25 Nevill AM, Stewart AD, Olds T, et al. Relationship between adiposity and body size reveals limitations of BMI. Am J Phys Anthropol 2006;129:151-6.

26 Paxton A, Lederman SA, Heymsfield SB, et al. Anthropometric equations for studying body fat in pregnant women. Am J Clin Nutr 1998;67:104-10.

27 Reichman NE, Nepomnyaschy L. Maternal pre-pregnancy obesity and diagnosis of asthma in offspring at age 3 years. Matern Child Health J 2008;12:725-33.

28 Chen Y, Rennie D, Cormier Y, et al. Association between obesity and atopy in adults. Int Arch Allergy Immunol 2010;153:372-7.

29 von Mutius E, Schwartz J, Neas LM, et al. Relation of body mass index to asthma and atopy in children: the National Health and Nutrition Examination Study III. Thorax 2001;56:835-8.

30 Crozier SR, Inskip HM, Godfrey KM, et al. Weight gain in pregnancy and childhood body composition: findings from the Southampton Women's Survey. Am J Clin Nutr 2012;91:1745-51

31 Challier JC, Basu S, Bintein T, et al. Obesity in pregnancy stimulates macrophage accumulation and inflammation in the placenta. Placenta 2008:29:274-81. 
32 Hendler I, Blackwell SC, Mehta SH, et al. The levels of leptin, adiponectin, and resistin in normal weight, overweight, and obese pregnant women with and without preeclampsia. Am J Obstet Gynecol 2005;193(3 Pt 2):979-83.

33 Tsuchiya T, Shimizu H, Horie T, et al. Expression of leptin receptor in lung: leptin as a growth factor. Eur J Pharmacol 1999;365:273-9.
34 Camargo CA Jr, Ingham T, Wickens K, et al. Cord-blood 25-hydroxyvitamin D levels and risk of respiratory infection, wheezing, and asthma. Pediatrics 2011;127:e180-7.

35 Jedrychowski W, Maugeri U, Flak E, et al. Predisposition to acute respiratory infections among overweight preadolescent children: an epidemiologic study in Poland. Public health 1998;112:189-95. 